\title{
Differential temporal activation of oxy- and deoxy-hemodynamic signals in optical imaging using functional near-infrared spectroscopy (fNIRS)
}

\author{
Nicoladie D Tam ${ }^{1 *}$, George Zouridakis ${ }^{2}$ \\ From 24th Annual Computational Neuroscience Meeting: CNS*2015 \\ Prague, Czech Republic. 18-23 July 2015
}

\begin{abstract}
Background
Optical imaging of the brain based on near-infrared spectroscopy (NIRS) can provide real-time measurements of the hemodynamic signals that represent metabolic demands of the underlying neural tissues. Functional imaging based on NIRS (fNIRS) can detect both oxyhemoglobin (oxy- $\mathrm{Hb})$ and deoxy-hemoglobin (deoxy- $\mathrm{Hb})$ levels related to neural metabolic activity, whereas BOLD fMRI (blood-oxygen-level dependent functional magnetic resonance imaging) can only detect signals related to deoxy-Hb. Thus, during task execution, only fNIRS can determine the differential temporal activation/deactivation of oxy-Hb and deoxy-Hb hemodynamic signals as the blood-oxygen demand changes. We have previously shown that as metabolic demand increases, temporal changes in oxy-Hb and deoxy-Hb levels can be temporally decoupled (i.e., oxy-Hb level can decrease while deoxy-Hb level increases) rather than being coupled, in which case both would increase or decrease simultaneously [1-5]. In order to account for the observed differential temporal decoupling of oxy- $\mathrm{Hb}$ and deoxy- $\mathrm{Hb}$ levels, we hypothesize that as oxygen demand increases, the delivery of blood oxygen cannot keep up with the demand of the neural tissues, resulting in decreased oxy-Hb and increased deoxy-Hb levels. This study provides experimental evidence that validates the above hypothesis.
\end{abstract}

\section{Methods}

Human subjects were recruited to execute voluntary arm movements in orthogonal directions to exert different

\footnotetext{
* Correspondence: nicoladie@tamunt.edu

'Department of Biological Sciences, University of North Texas, Denton, TX 76203, USA

Full list of author information is available at the end of the article
}

oxygen demands onto the motor cortex. The hemodynamic activities were recorded from the motor cortex using fNIRS, while the subjects executed predefined arm movements. The oxy-Hb and deoxy-Hb levels were computed from the NIRS optical signals using the modified Beer-Lambert law [6].

\section{Results:}

Figure 1 shows the differential changes of oxy- and deoxy-Hb hemodynamic signals over time during right and left movement directions. These data demonstrate that the oxy- and deoxy-Hb hemodynamic signals can change differentially rather than being coupled in time. The differential changes in oxy- and deoxy-Hb levels can be accounted by an oxygen demand exceeding the oxygen delivery in the blood vessels.

\section{Conclusions:}

The metabolic demands of the neural tissues are not necessarily correlated with either oxy- or deoxy-Hb alone, but they are correlated with the combination of both oxy- and deoxy-Hb. A decrease in oxy-Hb level does not necessarily imply that oxygen demand decreases. Rather, such a decrease in oxy-Hb level can be due to the rate of oxygen demand by the neural tissues that exceeds the oxygen delivery capacity of the blood vessels.

\footnotetext{
Authors' details

${ }^{1}$ Department of Biological Sciences, University of North Texas, Denton, TX 76203, USA. ${ }^{2}$ Departments of Engineering Technology, Computer Science, and Electrical and Computer Engineering, University of Houston, Houston, TX, 77204, USA.
}

Published: 18 December 2015 


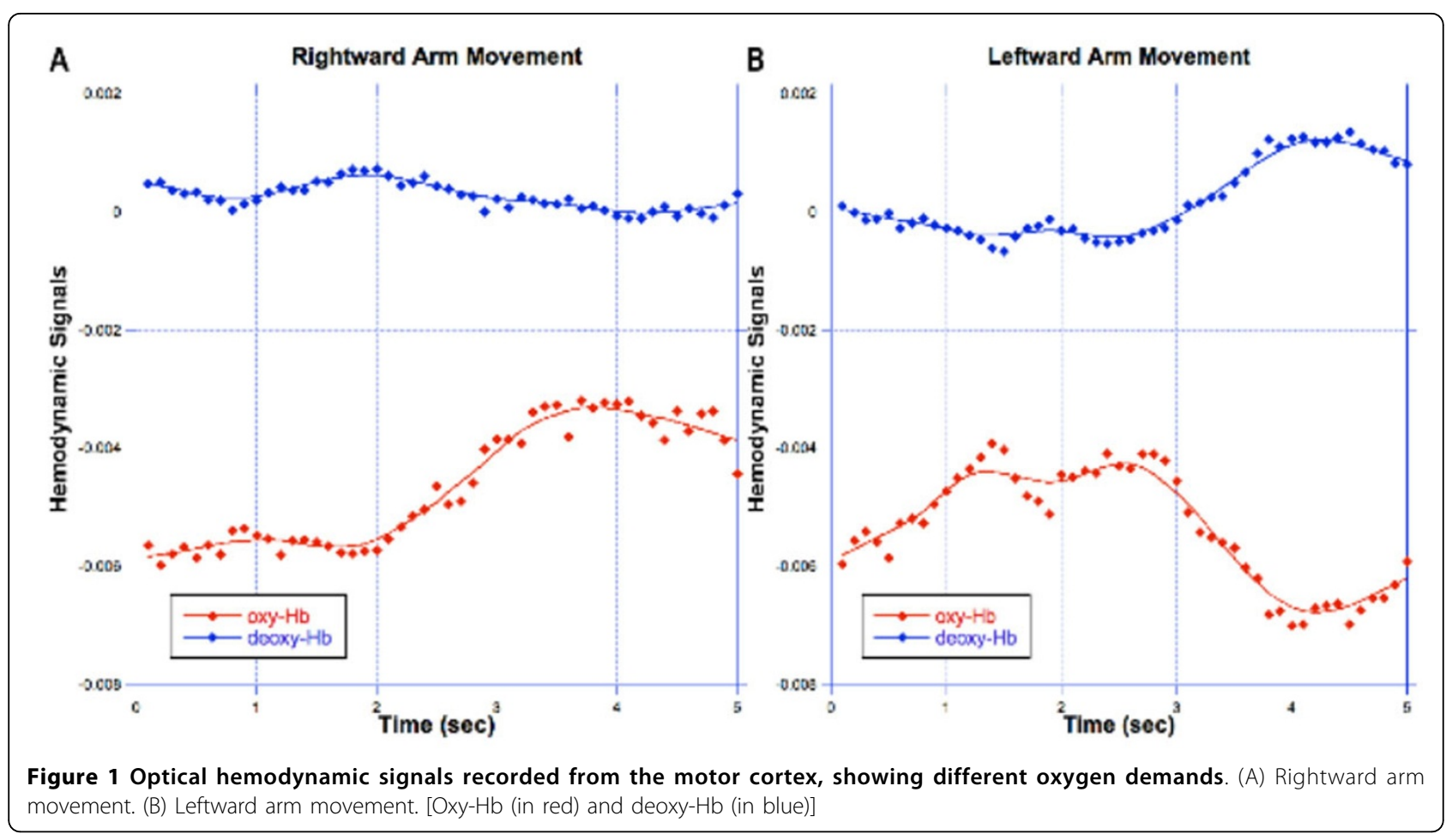

\section{References}

1. Tam ND, Zouridakis G: Optical imaging of motor cortical hemodynamic response to directional arm movements using near-infrared spectroscopy. International Journal of Biological Engineering 2013, 3(2):11-17.

2. Tam ND, Zouridakis G: Temporal decoupling of oxy- and deoxyhemoglobin hemodynamic responses detected by functional nearinfrared spectroscopy (fNIRS). Journal of Biomedical Engineering and Medical Imaging 2014, 1(2):18-28.

3. Tam ND, Zouridakis G: Decoding movement direction from motor cortex recordings using near-infrared spectroscopy. Infrared Spectroscopy: Theory, Developments and Applications Hauppauge, NY: Nova Science Publishers, Inc; 2014.

4. Tam ND, Zouridakis G: Decoding of movement direction using optical imaging of motor cortex. BMC Neuroscience 2013, 2013:P380, 8 July 2013.

5. Tam ND, Zouridakis G: Optical imaging of motor cortical activation using functional near-infrared spectroscopy. BMC Neuroscience 2012, 2012:P27, 16 July 2012.

6. Cope M, Delpy DT, Reynolds EO, Wray S, Wyatt J, van der Zee P: Methods of quantitating cerebral near infrared spectroscopy data. Advances in experimental medicine and biology 1988, 222:183-189.

doi:10.1186/1471-2202-16-S1-P245

Cite this article as: Tam and Zouridakis: Differential temporal activation of oxy- and deoxy-hemodynamic signals in optical imaging using functional near-infrared spectroscopy (fNIRS). BMC Neuroscience 2015 16(Suppl 1):P245.

\section{Submit your next manuscript to BioMed Central and take full advantage of:}

- Convenient online submission

- Thorough peer review

- No space constraints or color figure charges

- Immediate publication on acceptance

- Inclusion in PubMed, CAS, Scopus and Google Scholar

- Research which is freely available for redistribution 